Chal I enge for prevent ing medi cat i on errors- I ear $n$ fromerror s-: What is the nost effective I abel di spl ay to prevent medi cat i on error for i nj ect abl e drug?

\begin{tabular}{|l|l|}
\hline 著者 & Fur ukawa H r oyuki \\
\hline $\begin{array}{l}\text { j our nal or } \\
\text { publ i cat i on t i t l e }\end{array}$ & $\begin{array}{l}\text { Lect ure Not es i n Comput er Sci ence ( i ncl udi ng } \\
\text { subser i es Lect ure Not es i n Art i f i ci al } \\
\text { I nt el I i gence and Lect ure Not es i n } \\
\text { Bi oi nf or mat i cs) }\end{array}$ \\
\hline vol une & 4553 LNCS \\
\hline nunber & PART4 \\
\hline page r ange & 437- 442 \\
\hline year & 2007- 01- 01 \\
\hline URL & ht t p: //hdl . handl e. net /2297/9509 \\
\hline
\end{tabular}




\title{
Challenge for Preventing Medication Errors -Learn from Errors- : What Is the Most Effective Label Display to Prevent Medication Error for Injectable Drug?
}

\author{
Hiroyuki Furukawa \\ Center for Clinical Trial Management, Kanazawa University Hospital, \\ 13-1, Takara-machi, Kanazawa-city, Ishikawa, \\ 920-8641, Japan \\ sambista-knz@umin.ac.jp
}

\begin{abstract}
In the medical institutions, more than $50 \%$ of the error report is related to the administration of pharmaceuticals. And the half of the report is related to the administration of injectable drug.

By analyzing the error report, the inducing factor of medication error are not only the name similarity (sound alike) and the appearance similarity (look alike) of the preparations but also the display of the ingredient amount of the injectable drug which has 3 types ("X\% YmL", "Xmg/mL YmL", and "Xmg/YmL") .

The difficulty of the calculation seems to differ in these three types of display. Comparison of the right answer in these three types of display is tried for 6 subject groups which are three health care providers (physician, nurse and pharmacist) and their students. As a result, the calculation right answer percentage was high in "Xmg/YmL", "Xmg/mL YmL" and "X\% YmL" in turn.
\end{abstract}

Keywords: medication error, error inducing factor, display of the ingredient amount.

\section{Introduction}

In the medical institutions, more than $50 \%$ of the error report is related to the administration of pharmaceutical preparations. And the half of the report is related to the administration of injectable drug (Fig.1). By analyzing the error report, the major inducing factors of medication error are the name similarity (sound alike) and the appearance similarity (look alike) of the pharmaceutical preparations.

It is not easy to calculate the right dose of the injectable drug prescribed in clinical situation, and the calculation result can not be sufficiently confirmed in emergency condition. As a result, the wrong dose can be administered to patients without recognizing calculation error. 
By reviewing the measure to prevent calculation error in clinical setting, Ministry of Health, Labor and Welfare (MHLW) sent the notice to pharmaceutical companies on June $2^{\text {nd }}$ of 2004 in Japan (Fig.2).

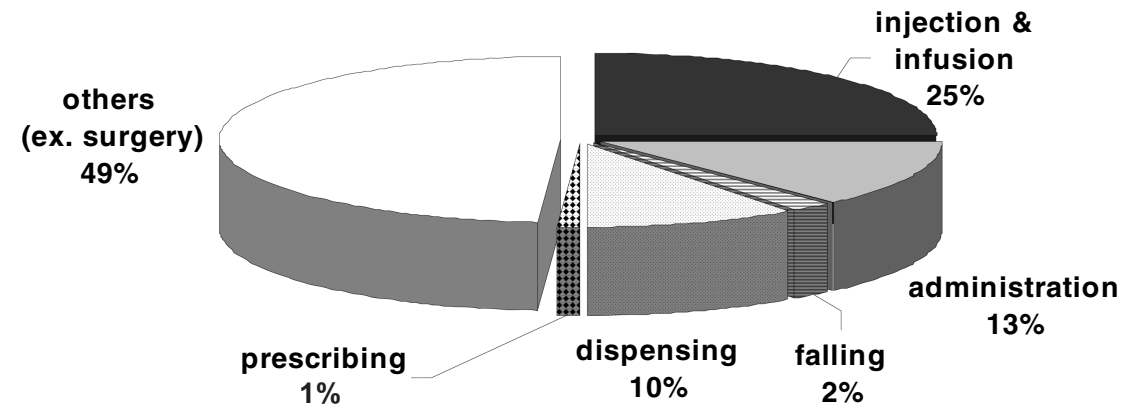

Fig. 1. Classification of Error Report in Japanese Medical Institution

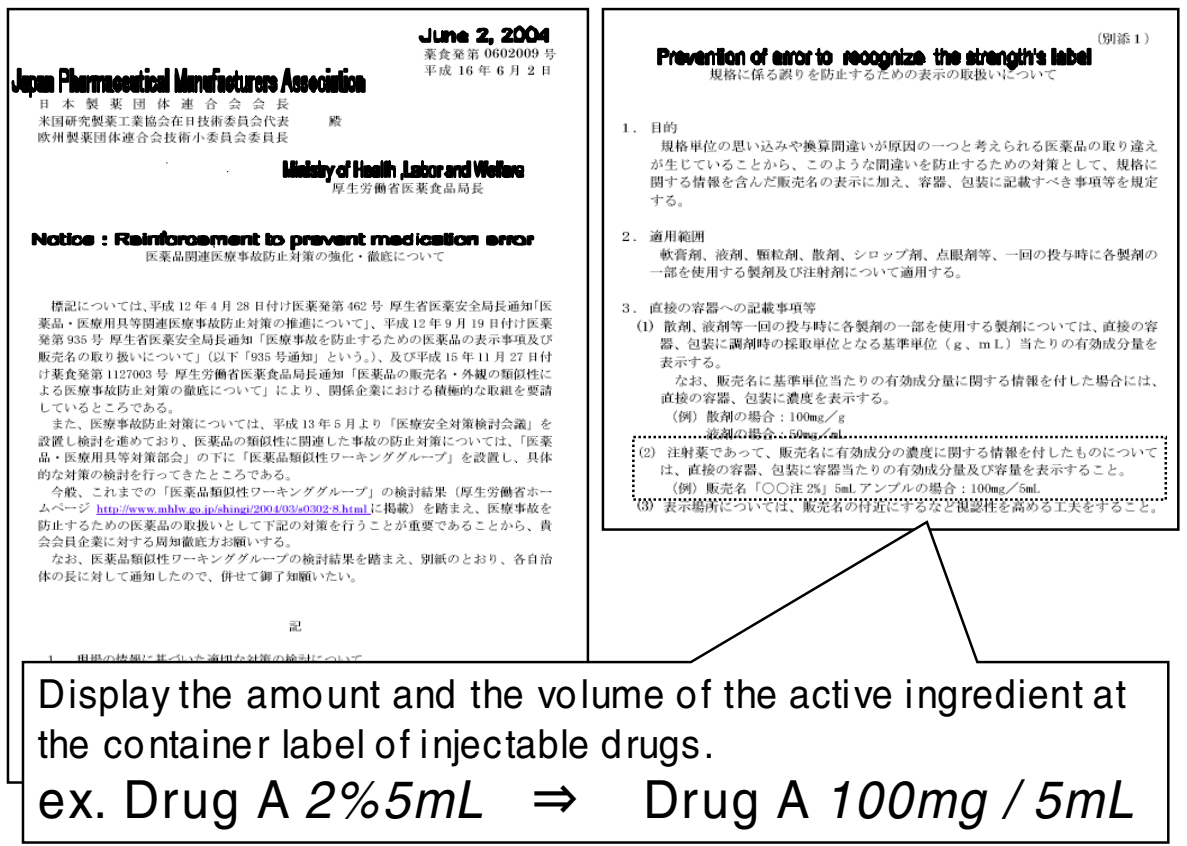

Fig. 2. Notice from MHLW : Reinforcement to Prevent Medication Error ( June 2, 2004 )

\section{Objective}

The label type of injectable drugs' strengths for preventing calculation errors is evaluated by comparing the correct answer rates to three label types, which are "X\% YmL", "Xmg/mL YmL", and "Xmg/YmL. 
Table 1. Number of Trial Subject

\begin{tabular}{lr}
\hline \multicolumn{1}{c}{ Subjects } & Number \\
\hline physician & 44 \\
Nurse & 506 \\
pharmacist & 206 \\
Medical Student & 85 \\
Nursing Student & 162 \\
Pharmacy Student & 211 \\
\hline
\end{tabular}

Q1 Physician ordered "Administer Xylocaine $® 30 \mathrm{mg}$, intravenously" . What " $\mathrm{mL}$ " should you administer to the patient ?

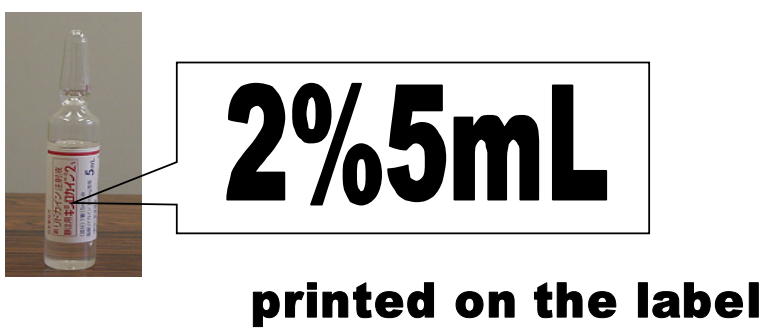

Fig. 3. Calculation Example A

Q2 Physician ordered "Administer Xylocaine ${ }^{\circ} 30 \mathrm{mg}$, intravenously".

What " $\mathrm{mL}$ " should you administer to the patient?

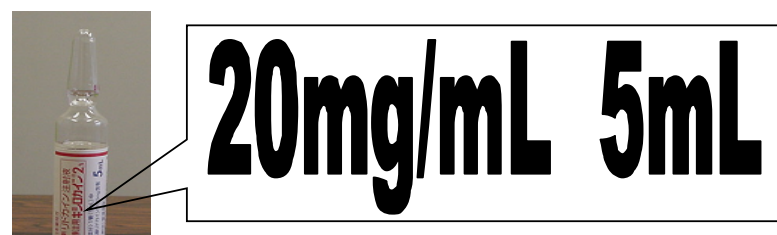

printed on the label

Fig. 4. Calculation Example B 


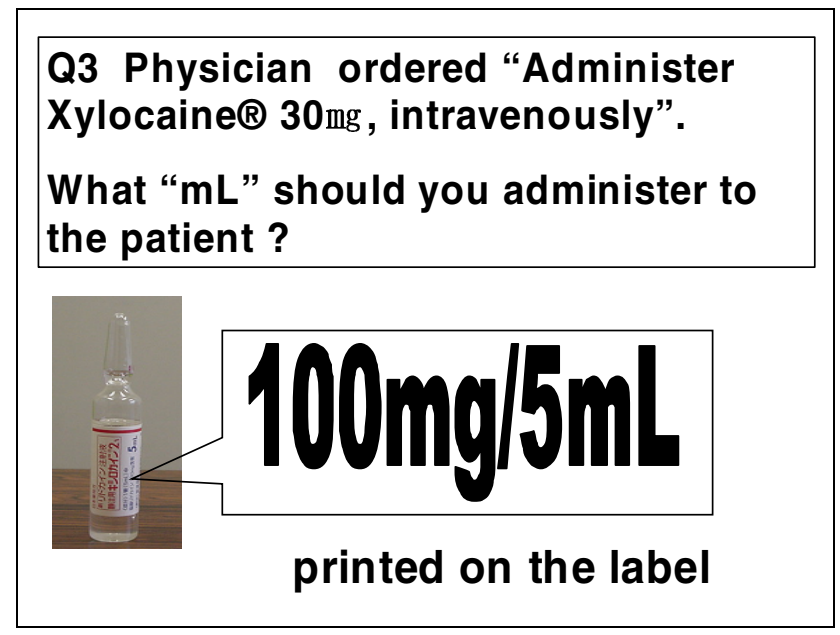

Fig. 5. Calculation Example $\mathrm{C}$

\section{Method}

In this research, two objects are investigated.

\subsection{Calculation of Dosage in Example Case}

Three label types are showed to three health care providers (physician, nurse, pharmacist) and their students by presentation of images on screen for 30 seconds (Table 1 , Fig.3-5).

Calculation of the dosage is tried by each health care providers and their students within the presentation time (30 seconds).

\subsection{Label Type of New Preparations}

Label type of new preparations marketed after the notice of MHLW was examined (June in 2004 - December in 2006).

\section{Results}

\subsection{Calculation of Dosage}

The correction rates to "X\% YmL" are $25.0 \%$ (physicians), $2.6 \%$ (nurses), $35.4 \%$ (pharmacists), "Xmg/mL YmL" are 79.5\% (physicians), 36.6\% (nurses), $72.6 \%$ (pharmacists), "Xmg/YmL" are 88.6\% (physicians), 51.2\% (nurses), $85.2 \%$ (pharmacists) (Fig.6).

In all surveyed health care providers, correction rates increased "X\% $\mathrm{YmL}$ ", "Xmg/mL YmL" and "Xmg/YmL" in turn, significantly $(\mathrm{p}<0.01$, chi-square test). And same results were observed in the health care students (Fig.7). 


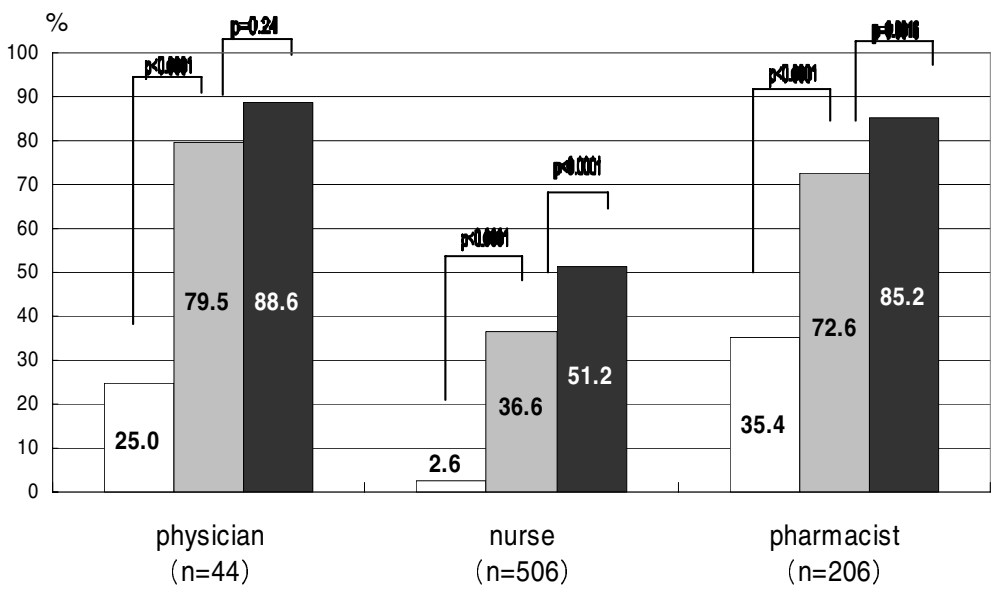

\section{$\square$ label:2\% $5 \mathrm{ml} \quad \square$ label: $20 \mathrm{mg} / \mathrm{mL} 5 \mathrm{ml} \quad \square$ label: $100 \mathrm{mg} / 5 \mathrm{~mL}$}

Fig. 6. Comparison of Right Calculation Percent in Each Health Care Providers (p:chi-square value)

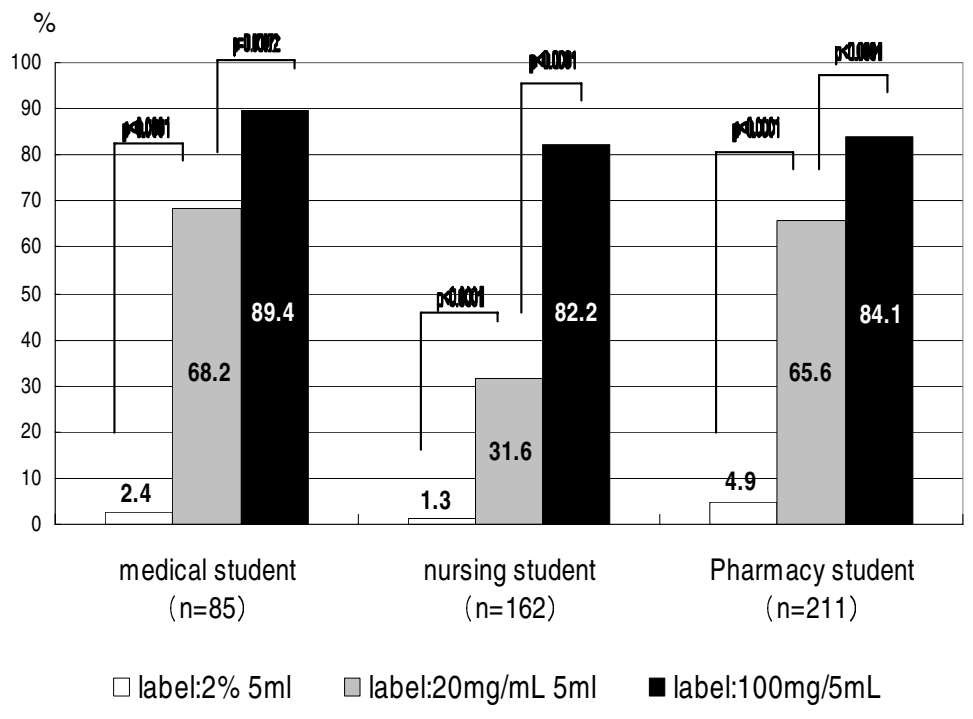

Fig. 7. Comparison of Right Calculation Percent in Each Health Care Students (p:chi-square value)

These results indicate the most effective label type to prevent calculation errors is " $\mathrm{Xmg} / \mathrm{YmL}$ " for injectable drugs' strengths. 


\subsection{Label Type of New Preparations}

The injectable drug which was marketed after the notice was 83 preparations (brand based), and 7 combination preparations, 5 transfusion preparations and 28 solid preparations to dissolve before use which can not display "Xmg/YmL" are 43 in 83 preparations (Fig.8).

Only 4 of 43 preparations which can display "Xmg/YmL" were displayed in "\%", and all of these 4 preparations are found "Xmg/YmL" on preparation label together.

As the result, "Xmg/YmL" were displayed in all of 43 preparation labels.

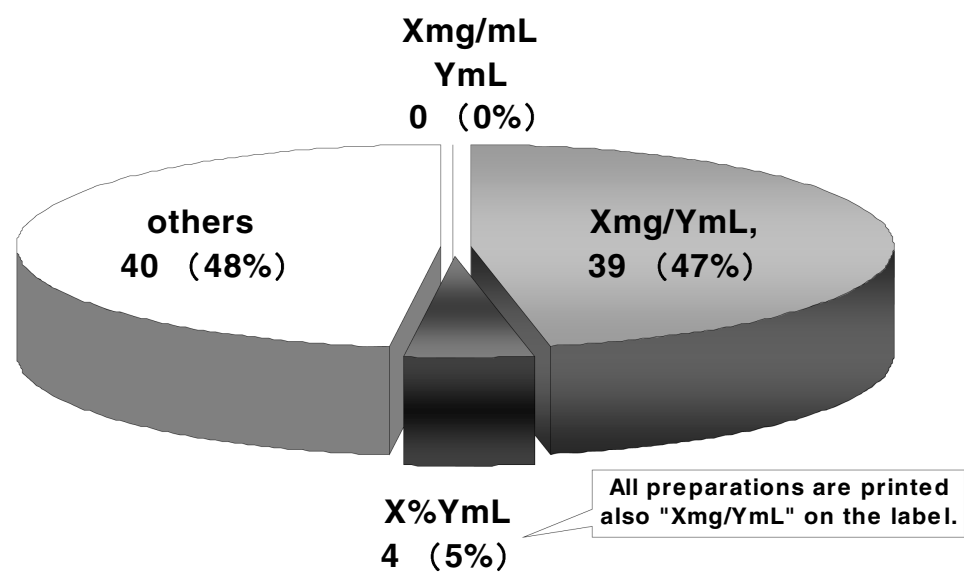

Fig. 8. Label type of new preparations marketed after the notice of MHLW

\section{Conclusion}

The most effective label type of injectable drugs' strengths for preventing calculation error is "Xmg/YmL" in this research, and the most effective "Xmg/YmL" is same as the indication in the notice from MHLW on June 4, 2004.

"Xmg/YmL" label is well accepted to the pharmaceutical companies after the notice of MHLW.

Acknowledgments. I appreciate all the health care providers and their students who cooperated with this investigation. 